\title{
Moderate Red Wine Consumption and Cardiovascular Disease Risk: Beyond the "French Paradox"
}

\author{
Giuseppe Lippi, M.D., 1,3 Massimo Franchini, M.D., 2,3 \\ Emmanuel J. Favaloro, Ph.D., M.A.I.M.S., ${ }^{4}$ and Giovanni Targher, M.D. ${ }^{5}$
}

The term French paradox was coined in 1992 to describe the relatively low incidence of cardiovascular disease in the French population, despite a relatively high dietary intake of saturated fats, and potentially attributable to the consumption of red wine. After nearly 20 years, several studies have investigated the fascinating, overwhelmingly positive biological and clinical associations of red wine consumption with cardiovascular disease and mortality. Light to moderate intake of red wine produces a kaleidoscope of potentially beneficial effects that target all phases of the atherosclerotic process, from atherogenesis (early plaque development and growth) to vessel occlusion (flow-mediated dilatation, thrombosis). Such beneficial effects involve cellular signaling mechanisms, interactions at the genomic level, and biochemical modifications of cellular and plasma components. Red wine components, especially alcohol, resveratrol, and other polyphenolic compounds, may decrease oxidative stress, enhance cholesterol efflux from vessel walls (mainly by increasing levels of high-density lipoprotein cholesterol), and inhibit lipoproteins oxidation, macrophage cholesterol accumulation, and foam-cell formation. These components may also increase nitric oxide bioavailability, thereby antagonizing the development of endothelial dysfunction, decrease blood viscosity, improve insulin sensitivity, counteract platelet hyperactivity, inhibit platelet adhesion to fibrinogen-coated surfaces, and decrease plasma levels of von Willebrand factor, fibrinogen, and coagulation factor VII. Light to moderate red wine consumption is also associated with a favorable genetic modulation of fibrinolytic proteins, ultimately increasing the surface-localized endothelial cell fibrinolysis. Overall, therefore, the "French paradox" may have its basis within a milieu containing several key molecules, so that favorable cardiovascular benefits might be primarily attributable to combined, additive, or perhaps synergistic effects of alcohol and other wine components on atherogenesis, coagulation, and fibrinolysis. Conversely, chronic heavy alcohol consumption and binge drinking are associated with increased risk of cardiovascular events. In conclusion, although mounting evidence strongly

${ }^{1}$ U.O. Diagnostica Ematochimica; ${ }^{2}$ Servizio di Immunoematologia e Medicina Trasfusionale; ${ }^{3}$ Dipartimento di Patologia e Medicina di Laboratorio, Azienda Ospedaliero-Universitaria di Parma, Parma, Italy; ${ }^{4}$ Department of Haematology, Institute of Clinical Pathology and Medical Research (ICPMR), Westmead Hospital, Westmead, Australia; ${ }^{5}$ Sezione di Endocrinologia e Malattie del Metabolismo, Dipartimento di Scienze Biomediche e Chirurgiche, Università di Verona, Verona, Italy.

Address for correspondence and reprint requests: Prof. Giuseppe Lippi, U.O. Diagnostica Ematochimica, Dipartimento di Patologia e Medicina di Laboratorio, Azienda Ospedaliero-Universitaria di Parma,
Strada Abbeveratoia, 2/a, 43100 - Parma Italy (e-mail: giuseppe.lippi @univr.it; giuseppe.lippi

Coagulopathies and Thrombosis: Usual and Unusual Causes and Associations, Part III; Guest Editors, Emmanuel J. Favaloro, Ph.D., M.A.I.M.S., Giuseppe Lippi, M.D., and Massimo Franchini, M.D. Semin Thromb Hemost 2010;36:59-70. Copyright (C) 2010 by Thieme Medical Publishers, Inc., 333 Seventh Avenue, New York, NY 10001, USA. Tel: +1(212) 584-4662.

DOI: http://dx.doi.org/10.1055/s-0030-1248725.

ISSN 0094-6176. 
supports beneficial cardiovascular effects of moderate red wine consumption (one to two drinks per day; $10-30 \mathrm{~g}$ alcohol) in most populations, clinical advice to abstainers to initiate daily alcohol consumption has not yet been substantiated in the literature and must be considered with caution on an individual basis.

KEYWORDS: Wine, cardiovascular disease, coronary artery disease, atherosclerosis

The term French paradox was coined from the epidemiological observation that some French populations suffered a relatively low incidence of coronary heart disease (CHD), despite a relatively high dietary intake of saturated fatty acids. This phenomenon, first described by the Irish physician Samuel Black in 1819, was later named the French paradox by Dr. Renaud, a scientist from Bordeaux University in France in $1992 .{ }^{1}$ In this controversial article, Renaud attributed this paradox to moderate red wine consumption. Although it had been postulated that moderate alcohol intake would prevent $\mathrm{CHD}$ by reducing atherosclerosis through beneficial effects on high-density lipoprotein-cholesterol (HDLC) levels, Renaud insisted that plasma HDL-C levels were not significantly higher in the French population than in those of other Western countries, so that other mechanisms should be advocated. After reevaluation of previously published studies, he concluded that the reduction in CHD did not appear to be due to an increase in HDL-C levels but rather to an improvement of the hemostatic balance, namely decreased platelet aggregability. ${ }^{1}$

According to the Food and Agriculture Organization (FAO) of the United Nations, ${ }^{2}$ the overall dietary fat consumption in France in 2003 (the last data available) was approximately $168 \mathrm{~g} / \mathrm{capita} /$ day as compared with $155 \mathrm{~g} /$ capita/day in the United States, $134 \mathrm{~g} /$ capita/day in the United Kingdom, and 126 g/capita/day in Sweden. The consumption of animal fat was $47 \mathrm{~g} /$ capita/day in France, 16 in the United States, 19 in the United Kingdom, and 52 in Sweden. Although the overall consumption of alcoholic beverages was $\sim 255$ g/capita/day in France, 269 in the United States, 340 in the United Kingdom, and 211 in Sweden, that of wine was $145 \mathrm{~g} /$ capita/day in France, 19 in the United States, 49 in the United Kingdom, and 47 in Sweden, so that wine consumption represented $\sim 57 \%$ of the overall consumption of alcoholic beverages in France, $7 \%$ in the United States, $15 \%$ in the United Kingdom, and 22\% in Sweden, respectively. However, according to the atlas of global epidemic of heart disease and stroke issued by the World Health Organization, ${ }^{3}$ in 2002 the mortality rate for CHD in France (0.8\%) was two to threefold lower than in the United States (1.8\%), United Kingdom (2.1\%), and Sweden (2.3\%). This is consistent with the earlier findings of Criqui and Ringel, who reported that despite a diet enriched in animal (saturated) fats and the highest wine intake worldwide, France had the second lowest CHD mortality rate in $1994 .{ }^{4}$ Now, nearly 20 years on from Renaud's original article, several experimental and epidemiological studies have investigated the fascinating association between red wine consumption and cardiovascular mortality and morbidity. Notably, some health researchers have questioned the validity of this relationship as explaining the paradox, whereas others have provided reliable evidences of biological and clinical plausibility to support the proposition.

\section{WINE}

In agreement with the observed relationship between moderate alcohol consumption and reduced risk for $\mathrm{CHD}$, it has been suggested that France's high red wine consumption could be the primary factor influencing the positive relationship. According to the 2007 state of the vitiviniculture world report issued by the International Organization of Wine and Vine, France is second only to Spain in terms of vineyards but is the leading country in terms of hectoliters of wine produced per year (around 50 million, which translates into 7 to 8 billion bottles per year). ${ }^{5}$ All common styles of wine-red, rosé, white (dry, semisweet, and sweet), sparkling, and fortified-are produced in France, and the country is the source of many grape varieties such as Cabernet Sauvignon, Chardonnay, Pinot Noir, Sauvignon Blanc, Syrah or Shiraz, Burgundy, and Bordeaux. In many respects, however, French wines have a more regional than national identity, as attested by different grape varieties, production methods, and classification systems in the various regions.

Although moderate alcohol intake from any type of alcoholic beverage appears to be beneficial for the cardiovascular system, ${ }^{6}$ several lines of evidence suggest that red wine might confer additional cardiovascular benefits. The first support for a more pronounced cardioprotective effect for red wine as compared with other alcoholic beverages emerged from the Copenhagen City Heart Study, where 13,285 men and women 30 to 70 years of age were followed for $\sim 12$ years and confirmed that the risk of cardiovascular mortality steadily decreased with increasing intakes of red wine, from a relative risk (RR) of 1.00 for the subjects who never drank wine to 0.51 (95\% confidence interval [CI], 
0.32 to 0.81 ) for those who drank three to five glasses per day. ${ }^{7}$ For spirits intake, however, the RR of dying increased from 1.00 for those who never drank to 1.34 (95\% CI, 1.05 to 1.71) for those with an intake of three to five drinks per day. A nonsignificant trend in mortality risk was also observed in relation to the subjects drinking beer compared with those who never drank beer. ${ }^{7}$

Although the primary ingredients of wine are water and alcohol, $>500$ compounds have been identified in wine to date, 160 of which are esters (reviewed by Soleas et al). ${ }^{8}$ Water, which represents from $80 \%$ to $85 \%$ of wine's total mass, derives from grape juice and it is thereby biologically pure. The alcohol content varies widely among wines (from $10 \%$ to $17 \%$ ) and is mainly attained by yeast-converting sugars. Besides adding their own characteristic flavors and odors, alcohols are the main carriers of aroma or bouquet. The most represented alcohol is ethanol; under standard fermentation conditions, it can accumulate to nearly 14 to $15 \%$, but generally ethanol concentrations are in a range between $10 \%$ and $13 \%$, depending on the sugar content of the grape, the temperature, and the yeast strain. Methanol, which is predominantly generated from the enzymatic breakdown of pectins, is a minor constituent of wine $(0.1$ to $0.2 \mathrm{~g} / \mathrm{L})$. Other alcohols present in wine include the straight-chain alcohols, especially 1-propanol, 2-methyl-1-propanol, 2-methyl-1-butanol, and 3-methyl-1-butanol. Glycerol is also present, and it usually adds a degree of sweetness. Acids (present from $0.4 \%$ to $1 \%$ ) give wine the sour or sharp aspect that enhances flavor when in balance with other components. Of the three organic acids that originate in grapes, tartaric acid is prevalent as the base measure of total acidity in wine, followed by malic and citric acids. Three other acids-succinic, lactic, and acetic (source of volatile acidity) — are also produced by fermentation. Although the grapes contain from $15 \%$ to $25 \%$ glucose and fructose, these sugars are mainly converted to alcohol through fermentation. However, traces of residual sugar $(0.1 \%)$ can be found in dry wines, whereas sweet wines may contain up to $10 \%$ sugars. Mineral salts (from $0.2 \%$ to $0.4 \%$ ), comprising mainly potassium, sodium, magnesium, calcium, and iron, are derived from mineral acids or organic acids. Flavoring and coloring substances (from $0.01 \%$ to $0.5 \%$ ) are mainly represented by polyphenolic compounds, and these give wines color and account for differences in flavor between reds and whites (their concentration is in fact much lower in white wines, $0.01 \%$ versus $0.2 \%$ in red wines). Phenols and related compounds can affect the appearance, taste, mouth feel, fragrance, and antimicrobial properties of the beverage. They come from the fruit (skins and seeds) and vine stems, with production by yeast metabolism, or extraction from wood cooperage. The two primary phenol groups present in wine are flavonoids and nonflavonoids. Again, these compounds are present in a larger amount in red than in white wines. Whereas red wines contain up to
1060 gallic acid equivalent (GAE) of flavonoids (namely catechins) and up to $235 \mathrm{GAE}$ of nonflavonoids (namely cinnamate derivatives), flavonoids and nonflavonoids are present at levels of 30 and $175 \mathrm{GAE}$, respectively, in white wines. Flavonols, namely tannins and anthocyanins, are exclusively present in red wines, at a concentration of 450 and $20 \mathrm{GAE}$, respectively. The concentration of phenolics in wine increases during skin fermentation but declines as phenols bond and precipitate with proteins and yeast hulls, so that aging has a dramatic effect on their final concentration. Traces of various chemical compounds of a volatile nature account for certain odors in wine. These include alcohols, aldehydes, esters, acids, and ketones. Sulfur derivatives are used to safeguard grapes and sterilize and preserve wines. The presence of sulfites at 10 to $200 \mathrm{ppm}$ (the upper limit for Italian wines) is measured both in fixed sulfur dioxide, combined with other substances, and free sulfur dioxide in the form of gas. ${ }^{8}$

Resveratrol $\left(3,4^{\prime}, 5\right.$ trihydroxystilbene) is a naturally occurring phytoalexin released by some spermatophytes such as grapevines in response to injury. Because it is mainly present in grape berry skins but not in flesh, and a major factor influencing its production is the fermentation time, white wine (which traditionally undergoes a shorter maceration time) contains only low amounts of resveratrol as compared with red wine. ${ }^{9}$ In rosé wines, the levels of resveratrol monomers are intermediate between those of white and red wines. The concentrations of the trans-isomer of resveratrol, the major isomer, vary widely in red wines originating from various countries, depending mainly on grape cultivar, geographic origin, wine type, Botrytis infection, and oenological practices. The highest concentrations of resveratrol are found in several red wines from France (Beaujolais, Midi, Rhone, Bordeaux, Burgundy; concentrations from 3.7 to $7.1 \mathrm{~g} / \mathrm{L}$,), Spain (Pinot Noir, Merlot, Grenache; from 2.5 to $14 \mathrm{mg} / \mathrm{L}$ ), and the United States (Muscadine up to $32 \mathrm{~g} / \mathrm{L}$ ). ${ }^{9}$

\section{THE FRENCH PARADOX: BIOLOGICAL AND EXPERIMENTAL EVIDENCE}

Several experimental studies suggest that the polyphenolic compounds in red wine, such as flavonoids and resveratrol, play an active role in preventing the development and progression of cardiovascular disease (CVD), possibly through a kaleidoscope of beneficial effects (Fig. 1). Reliable evidence, however, attests that the most favorable biological activities can be attributed to resveratrol and comprise inhibition of lipid peroxidation (lipoproteins, membranes), chelation of copper, freeradical scavenging, alteration of eicosanoid synthesis, inhibition of platelet aggregation, anti-inflammatory activity, improvement of endothelial function, lowering of blood pressure, vaso-relaxing activity, modulation of 


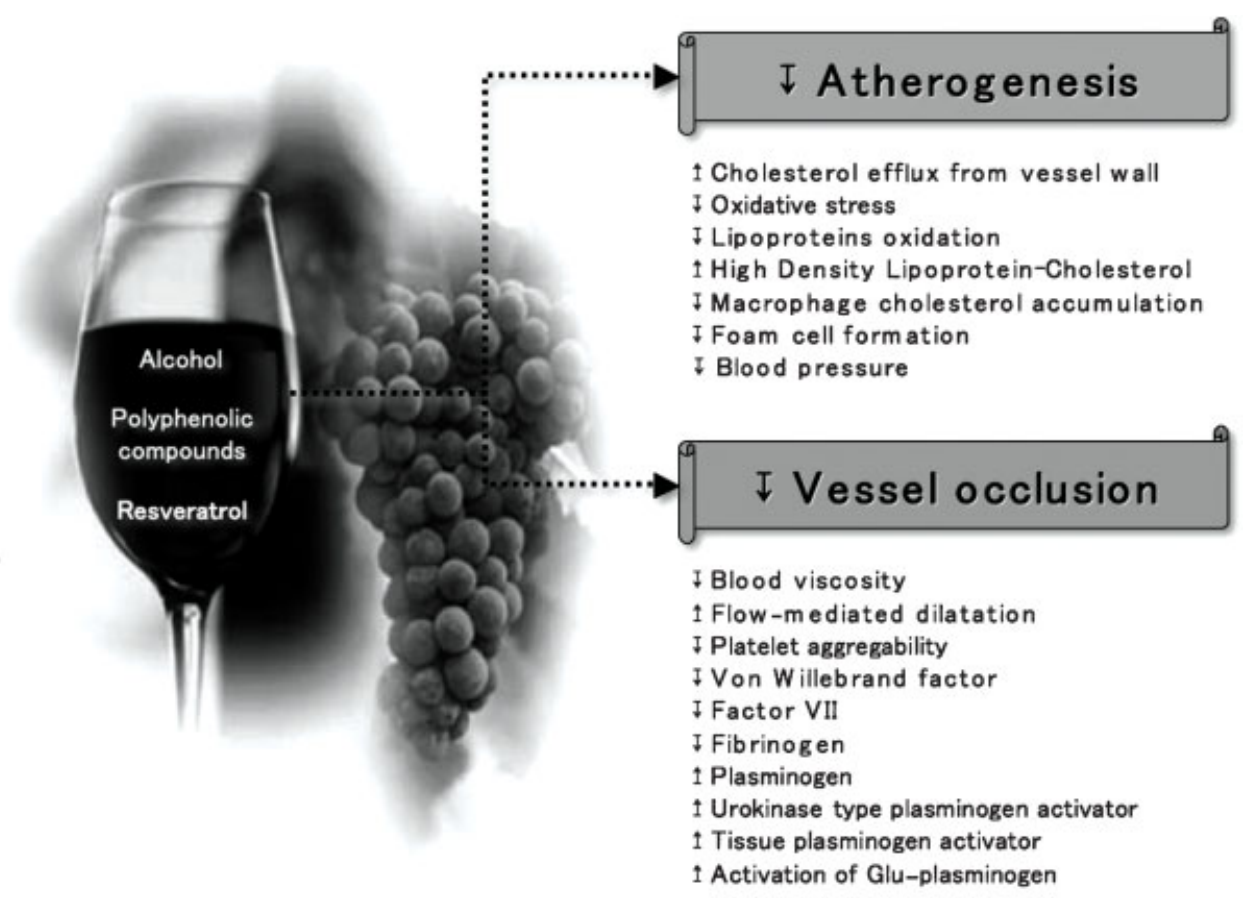

Figure 1 Favorable effects of wine components for counteracting the atherosclerotic process.

lipoprotein metabolism, activation of proteins that prevent cell senescence, and anticancer and estrogenic activity. ${ }^{10,11}$ Using microarray and quantitative realtime polymerase chain reaction methodologies, Nicholson et al demonstrated that beside biochemical interactions with cells and plasma components, treatment of human umbilical vein endothelial cells with resveratrol strongly modulates gene expression, leading to significant (more than twofold) downregulation of 363 genes and upregulation of 233 genes of the 10,000 genes present on the microarray. ${ }^{12}$

\section{Effects on Antioxidant Status, Oxidative Stress, and Lipoproteins}

Several studies have shown that dietary antioxidant intake can prevent the development and progression of $\mathrm{CVD}$, paving the way to the hypothesis that dietary antioxidants might be regarded as potential nonpharmacological agents because of the "oxidative theory" of atherosclerosis. ${ }^{13}$ Red wine contains a naturally rich source of antioxidants, which may protect the body from oxidative stress, and most of these beneficial effects have been primarily ascribed to resveratrol. Consumption of $400 \mathrm{~mL} /$ day of red wine for 2 weeks significantly increased antioxidant status and decreased oxidative stress in young and older subjects, as reflected by an increase in plasma total antioxidant status and significant decreases in both plasma malondialdehyde and whole blood glutathione. ${ }^{14}$ Likewise, plasma total phenolic concentrations increased significantly in healthy volunteers consuming $375 \mathrm{~mL}$ red wine daily for 2 weeks.
Trace levels of flavan-3-ol metabolites, mainly glucuronides and methyl glucuronides of (+)-catechin and (-)epicatechin, were also detected in the plasma of the red wine group but not in plasma from the control group. The maximum concentrations of conjugated dienes and thiobarbituric acid-reactive substances in $\mathrm{Cu}$-oxidized low-density lipoprotein-cholesterol (LDL-C) were reduced, whereas plasma HDL-C concentrations increased after moderate red wine consumption. ${ }^{15}$ Resveratrol was reported to protect LDL-C against ferrimyoglobin, peroxynitrite, copper, or 2 amidinopropane dihydrochloride-induced oxidation. ${ }^{16,17}$ Berrougui et al showed that resveratrol inhibited copper- and irradiation-induced LDL-C and HDL-C oxidation (as observed by a reduction in oxidation rate and an increase in the lag phase), concomitantly enhancing cholesterol efflux. ${ }^{18}$ Resveratrol also enhanced apolipoprotein A-1mediated cholesterol efflux, by upregulating ATP-binding cassette transporter 1 receptors, and reduced cholesterol influx or uptake in macrophages. Incubation of macrophages with $\mathrm{Fe} /$ ascorbate ions attenuated apolipoprotein A-1 and HDL-C mediated cholesterol efflux, whereas resveratrol (0 to $25 \mu \mathrm{M})$ significantly redressed this attenuation in a dose-dependent manner. ${ }^{18}$ Therefore, considering that lipoprotein oxidation, macrophage cholesterol accumulation, and foam-cell formation are important steps in early atherogenesis, resveratrol may be considered a natural antioxidant that enhances cholesterol efflux and could represent a nonpharmacological option to prevent the development and progression of CVD. More interestingly, resveratrol has also been proposed as a lifespan booster in several organisms, in 
that it might be vaso-protective by counteracting endothelial cell senescence. However, to counterbalance this hypothesis, Schilder et al showed that exposure of primary human endothelial cells to resveratrol was associated with increased levels of reactive oxygen species (ROS), which were causally linked to an accumulation of cells in the $\mathrm{S}$ phase of the cell cycle. Using a siRNA approach, two nicotinamide adenine dinucleotide phosphate (NADPH) oxidases were identified (Nox1 and Nox4) as major targets of resveratrol and primary sources of ROS that act upstream of the observed S-phase accumulation. In synthesis, chronic exposure to resveratrol was associated to prooxidant effects, by activating $\mathrm{NADPH}$ oxidases and inducing a premature senescent growth cell arrest in primary human endothelial cells, which possibly feeds back into ROS increase. ${ }^{19}$ Viniferin, catechin, and resveratrol isolated from grape skin strongly inhibit various isoforms of the cyclooxygenase enzyme, which plays an important role in inflammatory disorders, including atherosclerosis. ${ }^{20}$ Recently, resveratrol was shown to extend the lifespan in yeast through the activation of longevity gene SirT1, which is also responsible for the longevity mediated by calorie restriction. ${ }^{21}$

\section{Effects on Endothelial Function}

Endothelial dysfunction is an early marker of atherosclerosis and vessel damage, and it is a prognostic factor for CVD risk. In vitro studies have consistently demonstrated a variety of beneficial effects of red wine components on endothelial function. Directly acting on vascular smooth muscle cells, red wine components produce coronary vasodilation, attenuate oxidative stress in the heart (under different pathological conditions), and improve cardiac function in the ischemic myocardium through the protection of endothelial function, the expression of several cardioprotective oxidative stressinducible proteins, and the activation of adenosine receptors and nitrous oxide synthase mechanisms. ${ }^{22}$ In a single blind crossover study, Whelan et al reported that the consumption of $4 \mathrm{~mL} / \mathrm{kg}$ of either red or white wine with a light meal acutely improved brachial flowmediated dilatation after 6 hours, whereas blood-alcohol levels had returned to baseline values by this time; the magnitude of this effect on endothelial function was substantially similar after both red and white wines. ${ }^{23}$ Karatzi et al also observed that brachial flow-mediated dilatation was higher following the acute consumption of $250 \mathrm{~mL}$ of dealcoholized red wine than that following the acute consumption of red wine. ${ }^{24}$

Regarding the biological mechanisms linking endothelial function to moderate wine intake, it has been reported that alcohol per se can induce a marked increase in both basal and stimulated nitric oxide (NO) synthesis by primary cultures of bovine aortic endothelial cells and human umbilical endothelial cells, sustained by a rapid increase of endothelial NO synthase protein and mRNA expression levels. In particular, both endothelial NO synthase protein and mRNA increase by nearly twofold within 3 hours and gradually decline after $0.1 \%$ ethanol ingestion, but the increased levels of mRNA persist up to 24 hours. ${ }^{25}$ A 20 -hour treatment of human umbilical vein endothelial cells and of a human umbilical vein endothelial cells-derived cell line with an alcohol-free red wine polyphenol extract also led to a concentrationdependent increase (up to threefold) in NO release, associated with an up to twofold increased human endothelial NO synthase promotor activity. Remarkably, although polyphenol extracts from wines of specific origin and grape cultivars vary strongly in their individual activity, when averaged, the activity cannot be attributed to a specific grape cultivar or growing area. ${ }^{26}$ Resveratrol $(0.1 \mu \mathrm{mol} / \mathrm{L})$ also decreased the gene expression of the potent vasoconstrictor endothelin- $1 .^{27}$

Although the long-term beneficial effects of moderate red wine consumption on endothelial function are well established, currently there is still controversy about its acute (postprandial) effects, and not all wines seem to be equally effective. As such, a recent analysis of all available data about the acute effect of red wine constituents on endothelial function yielded inconclusive results, so that further larger studies are necessary to elucidate this matter. ${ }^{28}$

\section{Effects on Primary Hemostasis}

Consumption for a 4 -week period of $30 \mathrm{~g} /$ day of alcohol either from red wine or other alcoholic beverages resulted in similar decreases in collagen-induced platelet aggregation and plasma fibrinogen levels. However, adenosine diphosphate (ADP)-induced platelet aggregation was not affected by any treatment, and no significant differences were detected comparing platelet function at the end of red wine or dealcoholized treatments with findings at the end of alcohol treatment and abstinence, so that the beneficial effects of moderate red wine consumption on primary hemostasis appeared to be primarily due to the alcohol and not to the nonalcoholic fractions present in red wine. ${ }^{29}$ In a similar study by the same authors, consumption for a period of 4 weeks of nonalcoholic components either from $320 \mathrm{~mL}$ of red wine or from dealcoholized red wine resulted in similar increases in polyunsaturated fatty acids in all phospholipid fractions of platelets, with the exception of sphingomyelin. Thus the observed increase of polyunsaturated fatty acids in platelet phospholipids due to the nonalcoholic components of red wine suggests an antioxidant effect that could be relevant in explaining the beneficial effects of red wine reported in epidemiological studies. ${ }^{29}$

Collagen-induced platelet aggregation has been reported to be significantly reduced in subjects consuming two to four drinks per day of red wine (23 to $46 \mathrm{~g}$ of 
alcohol per day). ${ }^{30}$ Polagruto et al reported that a flavonol-rich grapeseed extract decreased significantly ADP-stimulated platelet reactivity at 1, 2, and 6 hours. Similarly, this extract decreased epinephrine-stimulated platelet reactivity 2 hours following consumption. ${ }^{31}$ Acute alcohol intake significantly increased platelet aggregation in suspension when stimulated with low concentrations of $\mathrm{ADP}(0.1$ and $0.5 \mathrm{ug} / \mathrm{mL})$. However, this effect was not observed when consuming the same amount of the alcohol contained in red wine. Conversely, adhesion to fibrinogen was inhibited by alcohol but not red wine at high shear rate after six drinks. This inhibition was accompanied by a reduction in aggregate size at 90 and 180 minutes after the start of the experiment. Adhesion to collagen was not altered by either alcohol or red wine intake. ${ }^{32}$

Although platelets are anuclear cellular elements, they might undergo apoptotic events as well. Lin et al showed that resveratrol ( 5 to $25 \mu \mathrm{M} / \mathrm{L}$ ) completely inhibits platelet aggregation stimulated by collagen, but it also stimulated in a time- and concentrationdependent manner the dissipation of the mitochondrial membrane potential (DeltaPsim), activation of caspases$9,-3$, and -8 , gelsolin and actin cleavage, Bid cleavage into truncated Bid, Bax translocation, cytochrome c release, and phosphatidylserine exposure in human platelets, which are well-known events leading to platelet apoptosis. ${ }^{33}$ Fehr et al showed that that, compared with water, an acute exposure to alcohol has only modest effects on hemorheological parameters and platelet aggregation in vivo and no effect in vitro, which suggests that other factors must be involved in both beneficial and harmful effects of wine consumption. ${ }^{34}$ As such, the evidence that resveratrol might simultaneously inhibit platelet aggregation and stimulate platelet apoptosis could represent an additional potential therapeutic option for preventing pathological outcomes in patients suffering from thrombotic conditions or thrombocytosis.

\section{Effects on Secondary Hemostasis and Fibrinolysis}

A meta-analysis of experimental studies assessing the effects of moderate alcohol intake on plasma HDL-C, apolipoprotein A-I, fibrinogen, triglycerides, and other cardiovascular risk biomarkers showed that a dose of $30 \mathrm{~g}$ of alcohol per day significantly increased the concentrations of plasma HDL-C by $8 \%$, apolipoprotein A-I by $7 \%$, plasminogen by $6 \%$, and tissue plasminogen activator (tPA) by 20\%. A nonsignificant trend toward lower levels of lipoprotein(a), fibrinogen, and von Willebrand factor (VWF) was also observed. Therefore, on the basis of published associations between these biomarkers and risk of $\mathrm{CHD}$, it was estimated that $30 \mathrm{~g}$ of alcohol/day would lead to a reduction of nearly $25 \%$ in overall CHD risk. ${ }^{35}$ Meaningful data about the relationship between alcohol consumption and secondary hemostasis were also provided by the Framingham Offspring Study. Levels of fibrinogen, plasma viscosity, VWF, factor VII, plasminogen activator inhibitor-1 (PAI-1), and tPA were measured in a cross-sectional analysis of 3223 U.S. adults free of CVD. Light-to-moderate alcohol consumption was associated with lower levels of fibrinogen, plasma viscosity, VWF, and factor VII. The association was most pronounced for consumers of 3 to 7 drinks weekly for viscosity, and 7 to 21 drinks weekly for other plasma hemostatic factors. Alcohol intake of 7 to 21 drinks weekly or more was also associated with impaired fibrinolytic activity, reflected by higher levels of tPA. Moreover, moderate wine drinkers had lower PAI-1 levels than other drinkers, particularly at 3 to 21 drinks weekly. ${ }^{36}$ In a further large epidemiological study, including 3158 men age 60 to 79 years, daily alcohol consumption showed a positive dose-response relationship with HDL-C, coagulation factor IX and tPA, and a negative dose-response relationship with fibrinogen and VWF after adjustment for potential confounders. Moreover, alcohol consumption showed a borderline negative association with D-dimer and no significant association with factors VII or VIII or C-reactive protein. ${ }^{37}$ Van Golde et al evaluated the acute changes in a large array of plasma hemostatic parameters 5 and 15 hours after the consumption of four (62.5 g of alcohol) and eight (125 g of alcohol) glasses of red wine, concluding that both doses of wine had no acute effects on activated cephalin time, thrombin-antithrombin complexes, factors VII and VIII, and VWF levels. ${ }^{38}$ In a further small experimental study, the same authors investigated the shortterm effects of three glasses of red wine daily during two periods of a week, with a week of abstinence from alcohol, in healthy male volunteers. Although some slight shifts in the various plasma hemostatic parameters could be noticed during these drinking periods, all favoring impairment rather than stimulation, no significant effects of moderate alcohol intake could be observed on fibrinolysis. ${ }^{39}$ With regard to lipoprotein(a), a highly atherogenic and antifibrinolytic lipoprotein particle, ${ }^{40}$ Sharpe et al demonstrated that $200 \mathrm{~mL}$ of red wine per day for 10 days are effective in lowering its plasma concentration by up to $12 \%{ }^{41}$ Surprisingly, this reduction was also observed with vodka but not with white wine, raising the issue of potential differences between various alcoholic drinks. ${ }^{42}$ Accordingly, it was also observed that serum lipoprotein (a) is inversely and dose-dependently related with alcohol intake in patients with hypertension, and this relationship was independent of the size distribution of apolipoprotein (a) isoforms. ${ }^{43}$ Therefore, it seems reasonable to conclude that reduction of lipoprotein (a) concentrations by regular consumption of alcohol might favorably affect the atherosclerotic risk profile and thereby decrease cardiovascular morbidity. 
An interesting study evaluating the acute effects of different alcoholic beverages on secondary hemostasis was performed by Tousoulis et al. Eighty-three healthy subjects were randomized into five groups to receive an equivalent dose of alcohol contained in four different alcoholic beverages $(264 \mathrm{~mL}$ red wine, $264 \mathrm{~mL}$ white wine, $633 \mathrm{~mL}$ beer, and $79 \mathrm{~mL}$ whiskey) and $250 \mathrm{~mL}$ water. ${ }^{44}$ Although no acute effect was observed in plasma lipid parameters in all study groups, VWF was significantly reduced by $9 \%$ and $14 \% 4$ hours after ingestion of red wine and beer, respectively. Conversely, the PAI-1-to-tPA ratio was increased by $64 \%, 85 \%$, and $79 \%$ after ingestion of white wine, beer, and whisky, respectively. No significant acute changes were observed in plasma fibrinogen and acute-phase reactants (i.e., Creactive protein, interleukin 6 , and tumor necrosis factor $\alpha)$. The short-term effects (5 to 24 hours) of a low (two glasses, $250 \mathrm{~mL}, 20 \mathrm{~g}$ alcohol) and a high (six glasses, $750 \mathrm{~mL}, 60 \mathrm{~g}$ alcohol) intake of red wine were also investigated in male volunteers. After the acute intake of two glasses of red wine, no clinically significant disturbances of plasma fibrinolysis were observed. However, 5 hours after the consumption of six glasses of red wine, a continued inhibition of fibrinolysis was evident, as mirrored by a dramatic 5- to 13-fold increase of PAI-1 activity and PAI-1 antigen. Although a modest rise of tPA antigen was also observed, tPA activity fell, as did plasmin-antiplasmin. ${ }^{45}$

Several in vitro studies also support the hypothesis that moderate red wine consumption may exert beneficial effects on fibrinolysis. Cultured human umbilical endothelial cells preincubated for 1 hour in the presence of ethanol (0.025 to $0.2 \%)$ showed a two- to fourfold increase of urokinase plasminogen activator receptor mRNA and antigen levels, associated with a 36\% increase of urokinase plasminogen activator ( $\mathrm{uPA}$ ) binding activity to endothelial cells. ${ }^{46}$ Low concentrations of ethanol (0.025 to $0.2 \%)$ also induced a short-term versus long-term increase in surface-localized fibrinolytic activity in cultured human umbilical endothelial cells via different mechanisms. Short-term effects were primarily mediated by alcohol-induced membrane conformational changes that simultaneously facilitate increased surfacelocalized plasminogen receptor availability and fibrinolytic protein/receptor interactions, resulting in increased tPA affinity for Glu-plasminogen and accelerated activation. The long-term effects were instead attributed primarily to the alcohol-induced increased availability of both newly synthesized tPA and plasminogen receptor and, hence, accelerated activation of Glu-plasminogen. ${ }^{47}$ Cultured human umbilical endothelial cells preincubated in the presence of varying concentrations of flavonoids such as catechin, epicatechin, quercetin, and resveratrol $(0.001$ to $10 \mu \mathrm{M} / \mathrm{L})$ also showed upregulation of both tPA and uPA gene transcription, resulting in the sustained increased expression of surface-localized fibrino- lytic activity by each of these phenolic compunds. ${ }^{47}$ These combined results are consistent with the hypothesis that low to moderate alcohol intake may induce a favorable genetic modulation of fibrinolytic proteins, ultimately increasing surface-localized endothelial cell fibrinolysis.

\section{Effects on Blood Pressure and Insulin Sensitivity}

Many observational studies have consistently shown a strong positive relationship between chronic heavy alcohol consumption (more than three drinks per day) and hypertension, thus supporting the current recommendations that daily alcohol reduction should represent an important component of lifestyle modification for the prevention and treatment of hypertension among heavy drinkers. ${ }^{48}$ Xin et al conducted a meta-analysis of randomized controlled trials to assess the effects of alcohol reduction on blood pressure. ${ }^{49}$ They included 15 randomized controlled trials (total of 2234 participants) in which alcohol reduction was the only intervention difference between active and control treatment groups. Overall, alcohol reduction was associated with a significant reduction in mean systolic and diastolic blood pressures of $-3 \mathrm{~mm} \mathrm{Hg}$ and $-2 \mathrm{~mm} \mathrm{Hg}$, respectively. The effect of alcohol reduction on blood pressure was consistent across subgroups, including those defined by presence or absence of hypertension. Furthermore, a dose-response relationship was observed between mean reduction in reported consumption of alcohol and net change in both systolic and diastolic blood pressure. However, because the participants included in these 15 clinical trials were fairly heavy alcohol drinkers (more than three drinks/day), this meta-analysis was unable to examine the long-term effect of moderate alcohol consumption on blood pressure, which at present remains not fully understood. A linear, J-shaped, or threshold association between alcohol consumption and blood pressure has been reported in some observational epidemiological studies. ${ }^{50-52}$ However, in controlled clinical studies that directly tested the effects of alcohol intake on blood pressure, findings are inconsistent, perhaps because of differences in duration of alcohol use and the timing of blood pressure measurements. In this setting, McFadden et al recently performed a systematic review of trials that measured blood pressure after a period of sustained alcohol intake (defined as daily intake of at least one alcoholic drink daily) in one group and that also included a control group of individuals who consumed no alcohol. ${ }^{53}$ Nine studies met the entrance criteria. This review demonstrated a significant rise in systolic blood pressure and diastolic blood pressure of $2.7 \mathrm{~mm} \mathrm{Hg}$ and $1.4 \mathrm{~mm} \mathrm{Hg}$, respectively, after alcohol intake. An early effect of alcohol leading to a reduction in blood pressure (in the hours after exposure) and a later effect (next day) of raising blood pressure led to smaller 
differences in the net effect of alcohol on blood pressure when ambulatory blood pressure monitoring measurements were compared with casual office- or clinic-based measurements. All of these findings indicate that the timing of blood pressure measurements after alcohol intake has a substantial effect on the magnitude and perhaps even the direction of blood pressure changes identified within any study.

Several epidemiological and intervention studies have examined the relationship between daily alcohol consumption and insulin sensitivity in individuals both with and without diabetes. For example, in a randomized crossover trial of 63 nondiabetic postmenopausal women, consumption of $30 \mathrm{~g} /$ day of alcohol (two drinks per day) significantly improved insulin sensitivity and decreased plasma insulin and triglyceride concentrations after 8 weeks of intervention when compared with placebo. ${ }^{54}$ In a multicenter randomized clinical intervention trial of subjects with type 2 diabetes who had previously abstained from alcohol, daily consumption of one alcoholic drink resulted in a reduction of fasting glucose after 30 days of intervention, and this relationship was stronger in subjects with higher hemoglobin A1c. ${ }^{55}$ Several other investigators have reported beneficial effects of moderate drinking on insulin sensitivity and glucose metabolism. ${ }^{56-59}$ Interestingly, the potentially beneficial changes in insulin sensitivity with moderate alcohol intake might help explain the results from several prospective observational studies showing a strong inverse association between moderate alcohol drinking and the risk of incident type 2 diabetes. ${ }^{60-62}$

\section{THE FRENCH PARADOX: CLINICAL AND EPIDEMIOLOGICAL EVIDENCE}

Although excessive amounts of red wine as well as other alcoholic beverages remain a definite risk for health, mild-to-moderate amounts of red wine may provide a net beneficial effect. Interest in the cardiovascular benefits of regular wine consumption has increased considerably over the past 30 years. ${ }^{63}$ In 1979 , St Leger and colleagues drew attention to the cardioprotective properties of wine when they described a strong inverse relationship between wine consumption and risk of death from CVD in various countries from Europe, North America, and Australasia. ${ }^{64}$ Since then, several epidemiological studies in different developed countries have analyzed the beneficial effects of regular wine consumption on the risk of CHD morbidity and mortality. ${ }^{1,7,65-71}$ A study conducted by Grønbaek and colleagues in 24,623 Danish subjects over 10 years investigated the chronic effect of one to three glasses of alcoholic beverage (beer or wine) per day on cardiovascular mortality. ${ }^{7}$ A beneficial effect of wine intake emerged from this study as subjects with lowto-moderate wine intake had half the risk (RR, $0.51 ; 95 \%$ CI, 0.32 to 0.81 ) of dying from cardiovascular causes as those who never drank wine, whereas beer and spirit drinkers did not experience this advantage. These results were reinforced when the same group of investigators performed a systematic review of large population-based cohort studies in which the type of alcohol consumed, smoking status, educational level, physical activity, and obesity were assessed at baseline. Compared with nondrinkers, light-to-moderate drinkers who avoided wine had a RR of death from all causes of 0.90 , whereas those who drank wine had a RR of 0.66 . The authors concluded that moderate wine intake may have a beneficial effect on all-cause mortality that is additive to the protection afforded by alcohol per se. ${ }^{69}$ Similar results emerged from a study conducted by Renaud and colleagues in 36,250 French middle-aged men where moderate red wine consumption but not of other alcoholic beverages reduced all-cause mortality over 18 years. ${ }^{72}$ Klatsky and colleagues followed up 128,934 adults in Northern California for up to 20 years ${ }^{71}$ and showed that light-to-moderate drinkers were at lower risk from $\mathrm{CHD}$ mortality (RR for 1 to 2 drinks per day $=0.7 ; 95 \% \mathrm{CI}, 0.6$ to 0.9 ). A preference for red wine consumption resulted in a lower RR for CHD mortality compared with liquor and beer. Heavy drinkers (six or more drinks per day) had a higher risk of noncardiovascular mortality than those who did not drink ( $R R=1.6 ; 95 \% \mathrm{CI}, 1.3$ to 2.0 ). In a large prospective study, Thun et al examined the longterm effect of alcohol consumption on mortality among middle-aged and elderly US adults. ${ }^{73}$ Of 490,000 men and women who reported their alcohol and tobacco use, 46,000 died during 9 years of follow-up. The authors compared the rates of all-cause and cause-specific mortality across categories of baseline alcohol consumption and adjusted for other prognostic risk factors. The cardiovascular mortality rates were $30 \%$ to $40 \%$ lower in men (RR, 0.7 ; $95 \% \mathrm{CI}, 0.7$ to 0.8 ) and women (RR, 0.6 ; $95 \% \mathrm{CI}$, 0.6 to 0.7 ) reporting at least one drink daily than those in nondrinkers. Moreover, the all-cause mortality rate was also lower among men and women reporting approximately one drink daily. Very recently, Djoussé et al examined the association between alcohol consumption and risk of CVD and death in 26,399 female participants from the Women's Health Study. ${ }^{74}$ They confirmed there was a J-shaped relation between alcohol consumption and incident CVD and total and CVD deaths in a multivariable model. Compared with abstainers, alcohol intake of 5 to $15 \mathrm{~g} /$ day was associated with $26 \%, 35 \%$, and $51 \%$ lower risk of CVD, total death, and CVD death, respectively. For CVD risk reduction, plasma lipids made the largest contribution to the lower risk of CVD, followed by hemoglobin A1c/diabetes, inflammatory/ hemostatic factors, and blood pressure factors. Overall, therefore, mounting evidence strongly supports the cardiovascular benefits of moderate alcohol consumption in most populations, with a dose-response relationship traditionally depicted as a "J-shaped" curve, being a 
moderate alcohol intake (10 to $30 \mathrm{~g} /$ day) beneficial and either no intake or an excessive intake $(>30 \mathrm{~g} /$ day) harmful. ${ }^{75}$ A J-shaped relationship also emerged from a meta-analysis published in 2002 by Di Castelnuovo and colleagues. ${ }^{65}$ In this meta-analysis including 26 prospective studies with $>200,000$ persons, the RR for CHD of wine drinkers in respect to nondrinkers was 0.68 (95\% CI, 0.59 to 0.77$)$, whereas the benefit associated with beer drinking was $10 \%$ lower (RR $0.78 ; 95 \% \mathrm{CI}, 0.70$ to 0.86). The same authors more recently published a comprehensive meta-analysis of alcohol consumption and all-cause mortality in 34 prospective studies totaling more than a million subjects. ${ }^{76}$ Again, they confirmed a strong J-shaped relationship between all-cause mortality and alcohol intake, showing that light-to-moderate amounts of wine (one to two drinks per day in women and two to three drinks per day in men) are inversely associated with total mortality in both men and women (maximum protection was $18 \%$ in women and $17 \%$ in men).

Although several clinical studies have to date investigated the role of wine intake on cardiovascular health, only a few controlled trials have directly compared red wine with other alcoholic beverages. ${ }^{77-81}$ The type of alcohol-containing beverage consumed does not appear to make a difference on the risk for CHD in a cohort of 38,077 U.S. male health professionals over 12 years of follow-up. ${ }^{70}$ Similar mortality risk reductions were also found to be associated with red wine, white wine, other types of wine, and combinations of wine types in the cohort study conducted by Klatsky and colleagues. ${ }^{71}$ In a recent review on this topic, it was concluded that the CVD risk appeared to be more strongly related to the drinking pattern than to the type of alcoholic drinks consumed. ${ }^{82}$ Overall, therefore, the current evidence is not conclusive, and a clear and definite answer to the hypothesized superiority of red wine to other alcoholic beverages could only arise from future large well-designed prospective randomized trials.

However, there does exist some important evidence in favor of a potentially cardioprotective effect of red wine not related to alcohol, and these come from experimental studies evaluating the acute intake of dealcoholized red wine. Karatzi and colleagues investigated the acute intake of $250 \mathrm{~mL}$ dealcoholized red wine on endothelial function in 15 men with angiographically documented $\mathrm{CHD},{ }^{83}$ and they found that it decreased arterial stiffness and improved the augmentation index, as derived from arterial wave reflection patterns. The same group of investigators observed that a similar dose of alcohol-free red wine decreased adverse postsmoking arterial wave reflections and lessened the rise in systolic blood pressure. ${ }^{84}$ Other experimental studies found that brachial artery flow-mediated vasodilation was improved by the acute intake of 250 to $500 \mathrm{~mL}$ of dealcoholized red wine. ${ }^{85,86}$

\section{CONCLUSIONS}

Wine has been part of human culture for $>3000$ years, serving dietary and socioreligious functions. Its production takes place on every continent, and its chemical composition is profoundly influenced by oenological techniques, the grape cultivar from which it originates, and climatic factors. ${ }^{8}$ Several prospective studies have consistently demonstrated that light-to-moderate red wine consumption (one to two drinks per day; 10 to $30 \mathrm{~g}$ alcohol) is strongly associated with a lower incidence of CVD events compared with abstinence or occasional alcohol consumption. Most studies have reported a J-shaped association, with no consumption or chronic heavy consumption of wine (three or more drinks per day) and other alcoholic beverages associated with increased CVD risk compared with moderate consumption. Globally, the cardiovascular benefits of wine are likely due to combined, additive, or perhaps synergistic effects of alcohol and other wine components (mainly resveratrol and other polyphenolic compounds) on atherogenesis, coagulation, and fibrinolysis.

Although there is now also growing evidence that suggests moderate red wine intake might represent a promising "therapeutic" option to prevent and perhaps even treat CVD, some doubts still remain. First, it is still unclear whether the beneficial effects of red wine intake can be attributed to any specific type of grape(s), and therefore any single wine source cannot be considered better than any other. Second, it remains to be determined whether the reported beneficial benefits of alcoholic beverages in general, and of red wine in particular, are biased by one or more socioeconomic confounders. Accordingly, the beneficial effects of red wine intake in human health should be better defined, and additional research is required before any firm recommendation can be made to abstainers to initiate a light to moderate consumption of red wine.

\section{REFERENCES}

1. Renaud S, de Lorgeril M. Wine, alcohol, platelets, and the French paradox for coronary heart disease. Lancet 1992; 339(8808):1523-1526

2. Food and Agriculture Organization of the United Nations. Available at: http://faostat.fao.org/site/345/default.aspx. Accessed September 15, 2009

3. World Health Organization. Atlas of global epidemic of heart disease and stroke. Available at: http://www.who.int/ cardiovascular_diseases/en/cvd_atlas_29_world_data_table.pdf. Accessed September 15, 2009

4. Criqui $\mathrm{MH}$, Ringel BL. Does diet or alcohol explain the French paradox? Lancet 1994;344(8939-8940):1719-1723

5. International Organization of Wine and Vine. State of the vitiviniculture world report in 2007. Available at: http:// news.reseau-concept.net/images/oiv_uk/client/STATISTIQUE__Verone_2008_EN_definitif_41diapos.pps. Accessed September 15, 2009 
6. Szmitko PE, Verma S. Cardiology patient pages. Red wine and your heart. Circulation 2005;111(2):e10-e11

7. Grønbaek M, Deis A, Sørensen TI, Becker U, Schnohr P, Jensen G. Mortality associated with moderate intakes of wine, beer, or spirits. BMJ 1995;310(6988):1165-1169

8. Soleas GJ, Diamandis EP, Goldberg DM. Wine as a biological fluid: history, production, and role in disease prevention. J Clin Lab Anal 1997;11(5):287-313

9. Frémont L. Biological effects of resveratrol. Life Sci 2000; 66(8):663-673

10. Pellegrini N, Simonetti P, Brusamolino A, Bottasso B, Pareti FI. Composition of platelet phospholipids after moderate consumption of red wine in healthy volunteers. Eur J Clin Nutr 1996;50(8):535-544

11. Dohadwala MM, Vita JA. Grapes and cardiovascular disease. J Nutr 2009;139(9):1788S-1793S

12. Nicholson SK, Tucker GA, Brameld JM. Effects of dietary polyphenols on gene expression in human vascular endothelial cells. Proc Nutr Soc 2008;67(1):42-47

13. Kaliora AC, Dedoussis GV, Schmidt H. Dietary antioxidants in preventing atherogenesis. Atherosclerosis 2006; 187(1):1-17

14. Micallef M, Lexis L, Lewandowski P. Red wine consumption increases antioxidant status and decreases oxidative stress in the circulation of both young and old humans. Nutr J 2007;6:27

15. Tsang C, Higgins S, Duthie GG, et al. The influence of moderate red wine consumption on antioxidant status and indices of oxidative stress associated with CHD in healthy volunteers. Br J Nutr 2005;93(2):233-240

16. Zou J, Huang Y, Chen Q, Wei E, Cao K, Wu JM. Effects of resveratrol on oxidative modification of human low density lipoprotein. Chin Med J (Engl) 2000;113(2):99-102

17. Frémont L, Belguendouz L, Delpal S. Antioxidant activity of resveratrol and alcohol-free wine polyphenols related to LDL oxidation and polyunsaturated fatty acids. Life Sci 1999; 64(26):2511-2521

18. Berrougui H, Grenier G, Loued S, Drouin G, Khalil A. A new insight into resveratrol as an atheroprotective compound: Inhibition of lipid peroxidation and enhancement of cholesterol efflux. Atherosclerosis 2009;207(2):420-427

19. Schilder YD, Heiss EH, Schachner D, et al. NADPH oxidases 1 and 4 mediate cellular senescence induced by resveratrol in human endothelial cells. Free Radic Biol Med 2009;46(12):1598-1606

20. Leifert WR, Abeywardena MY. Cardioprotective actions of grape polyphenols. Nutr Res 2008;28(11):729-737

21. Lekli I, Ray D, Das DK. Longevity nutrients resveratrol, wines and grapes. Genes Nutr 2009; September 4 (Epub ahead of print)

22. Das S, Santani DD, Dhalla NS. Experimental evidence for the cardioprotective effects of red wine. Exp Clin Cardiol 2007;12(1):5-10

23. Whelan AP, Sutherland WH, McCormick MP, Yeoman DJ, de Jong SA, Williams MJ. Effects of white and red wine on endothelial function in subjects with coronary artery disease. Intern Med J 2004;34(5):224-228

24. Karatzi K, Papamichael C, Aznaouridis K, et al. Constituents of red wine other than alcohol improve endothelial function in patients with coronary artery disease. Coron Artery Dis 2004;15(8):485-490

25. Venkov CD, Myers PR, Tanner MA, Su M, Vaughan DE. Ethanol increases endothelial nitric oxide production through modulation of nitric oxide synthase expression. Thromb Haemost 1999;81(4):638-642

26. Leikert JF, Räthel TR, Wohlfart P, Cheynier V, Vollmar AM, Dirsch VM. Red wine polyphenols enhance endothelial nitric oxide synthase expression and subsequent nitric oxide release from endothelial cells. Circulation 2002;106(13):1614-1617

27. Nicholson SK, Tucker GA, Brameld JM. Effects of dietary polyphenols on gene expression in human vascular endothelial cells. Proc Nutr Soc 2008;67(1):42-47

28. Karatzi K, Karatzis E, Papamichael C, Lekakis J, Zampelas A. Effects of red wine on endothelial function: postprandial studies vs clinical trials. Nutr Metab Cardiovasc Dis 2009; 19(10):744-750

29. Pellegrini N, Pareti FI, Stabile F, Brusamolino A, Simonetti P. Effects of moderate consumption of red wine on platelet aggregation and haemostatic variables in healthy volunteers. Eur J Clin Nutr 1996;50(4):209-213

30. Pikaar NA, Wedel M, van der Beek EJ, et al. Effects of moderate alcohol consumption on platelet aggregation, fibrinolysis, and blood lipids. Metabolism 1987;36(6):538543

31. Polagruto JA, Gross HB, Kamangar F, et al. Platelet reactivity in male smokers following the acute consumption of a flavanolrich grapeseed extract. J Med Food 2007;10(4):725-730

32. de Lange DW, Hijmering ML, Lorsheyd A, et al. Rapid intake of alcohol (binge drinking) inhibits platelet adhesion to fibrinogen under flow. Alcohol Clin Exp Res 2004;28(10): 1562-1568

33. Lin KH, Hsiao G, Shih CM, Chou DS, Sheu JR. Mechanisms of resveratrol-induced platelet apoptosis. Cardiovasc Res 2009;83(3):575-585

34. Fehr M, Galliard-Grigioni KS, Reinhart WH. Influence of acute alcohol exposure on hemorheological parameters and platelet function in vivo and in vitro. Clin Hemorheol Microcirc 2008;39(1-4):351-358

35. Rimm EB, Williams P, Fosher K, Criqui M, Stampfer MJ. Moderate alcohol intake and lower risk of coronary heart disease: meta-analysis of effects on lipids and haemostatic factors. BMJ 1999;319(7224):1523-1528

36. Mukamal KJ, Jadhav PP, D’Agostino RB, et al. Alcohol consumption and hemostatic factors: analysis of the Framingham Offspring cohort. Circulation 2001;104(12):1367-1373

37. Wannamethee SG, Lowe GD, Shaper G, et al. The effects of different alcoholic drinks on lipids, insulin and haemostatic and inflammatory markers in older men. Thromb Haemost 2003;90(6):1080-1087

38. van Golde PM, Kraaijenhagen RJ, Bouma BN, van de Wiel A. No acute effect of red wine on the coagulation pathway in healthy men. Alcohol 2003;29(3):183-186

39. van Golde PM, Hart HCh, Kraaijenhagen RJ, Bouma BN, van de Wiel A. Regular alcohol intake and fibrinolysis. Neth J Med 2002;60(7):285-288

40. Lippi G, Guidi G. Lipoprotein(a): an emerging cardiovascular risk factor. Crit Rev Clin Lab Sci 2003;40(1):1-42

41. Sharpe PC, McGrath LT, McClean E, Young IS, Archbold GP. Effect of red wine consumption on lipoprotein (a) and other risk factors for atherosclerosis. QJM 1995;88(2):101108

42. Sharpe PC, Young IS, Evans AE. Effect of moderate alcohol consumption on $\mathrm{lp}$ (a) lipoprotein concentrations. Reduction is supported by other studies. BMJ 1998;316(7145):1675

43. Catena C, Novello M, Dotto L, De Marchi S, Sechi LA. Serum lipoprotein(a) concentrations and alcohol consumption 
in hypertension: possible relevance for cardiovascular damage. J Hypertens 2003;21(2):281-288

44. Tousoulis D, Ntarladimas I, Antoniades C, et al. Acute effects of different alcoholic beverages on vascular endothelium, inflammatory markers and thrombosis fibrinolysis system. Clin Nutr 2008;27(4):594-600

45. van de Wiel A, van Golde PM, Kraaijenhagen RJ, von dem Borne PA, Bouma BN, Hart HC. Acute inhibitory effect of alcohol on fibrinolysis. Eur J Clin Invest 2001;31(2):164-170

46. Tabengwa EM, Grenett HE, Benza RL, et al. Ethanolinduced up-regulation of the urokinase receptor in cultured human endothelial cells. Alcohol Clin Exp Res 2001;25(2): $163-170$

47. Abou-Agag LH, Tabengwa EM, Tresnak JA, Wheeler CG, Taylor KB, Booyse FM. Ethanol-induced increased surfacelocalized fibrinolytic activity in cultured human endothelial cells: kinetic analysis. Alcohol Clin Exp Res 2001;25(3): 351-361

48. Campbell NR, Ashley MJ, Carruthers SG, Lacourcière Y, McKay DW. Lifestyle modifications to prevent and control hypertension. 3. Recommendations on alcohol consumption. Canadian Hypertension Society, Canadian Coalition for High Blood Pressure Prevention and Control, Laboratory Centre for Disease Control at Health Canada, Heart and Stroke Foundation of Canada. CMAJ 1999;160(9, suppl): S13-S20

49. Xin X, He J, Frontini MG, Ogden LG, Motsamai OI, Whelton PK. Effects of alcohol reduction on blood pressure: a meta-analysis of randomized controlled trials. Hypertension 2001;38(5):1112-1117

50. He J, Bazzano LA. Effects of lifestyle modification on treatment and prevention of hypertension. Curr Opin Nephrol Hypertens 2000;9(3):267-271

51. Keil U, Liese A, Filipiak B, Swales JD, Grobbee DE. Alcohol, blood pressure and hypertension. Novartis Found Symp 1998;216:125-144; discussion 144-151

52. Beilin LJ, Puddey IB. Alcohol, hypertension and cardiovascular disease-implications for management. Clin Exp Hypertens 1993;15(6):1157-1170

53. McFadden CB, Brensinger CM, Berlin JA, Townsend RR. Systematic review of the effect of daily alcohol intake on blood pressure. Am J Hypertens 2005;18(2 Pt 1):276-286

54. Davies MJ, Baer DJ, Judd JT, Brown ED, Campbell WS, Taylor PR. Effects of moderate alcohol intake on fasting insulin and glucose concentrations and insulin sensitivity in postmenopausal women: a randomized controlled trial. JAMA 2002;287(19):2559-2562

55. Shai I, Wainstein J, Harman-Boehm I, et al. Glycemic effects of moderate alcohol intake among patients with type 2 diabetes: a multicenter, randomized, clinical intervention trial. Diabetes Care 2007;30(12):3011-3016

56. Sierksma A, Patel H, Ouchi N, et al. Effect of moderate alcohol consumption on adiponectin, tumor necrosis factoralpha, and insulin sensitivity. Diabetes Care 2004;27(1):184189

57. Djoussé L, Biggs ML, Mukamal KJ, Siscovick DS. Alcohol consumption and type 2 diabetes among older adults: the Cardiovascular Health Study. Obesity (Silver Spring) 2007; 15(7):1758-1765

58. Brand-Miller JC, Fatema K, Fatima K, et al. Effect of alcoholic beverages on postprandial glycemia and insulinemia in lean, young, healthy adults. Am J Clin Nutr 2007;85(6): $1545-1551$
59. Joosten MM, Beulens JW, Kersten S, Hendriks HF. Moderate alcohol consumption increases insulin sensitivity and ADIPOQ expression in postmenopausal women: a randomised, crossover trial. Diabetologia 2008;51(8):13751381

60. Stampfer MJ, Colditz GA, Willett WC, et al. A prospective study of moderate alcohol drinking and risk of diabetes in women. Am J Epidemiol 1988;128(3):549-558

61. Wannamethee SG, Camargo CA Jr, Manson JE, Willett WC, Rimm EB. Alcohol drinking patterns and risk of type 2 diabetes mellitus among younger women. Arch Intern Med 2003;163(11):1329-1336

62. Koppes LL, Dekker JM, Hendriks HF, Bouter LM, Heine RJ. Moderate alcohol consumption lowers the risk of type 2 diabetes: a meta-analysis of prospective observational studies. Diabetes Care 2005;28(3):719-725

63. Providência R. Cardiovascular protection from alcoholic drinks: scientific basis of the French Paradox. Rev Port Cardiol 2006;25(11):1043-1058

64. St Leger AS, Cochrane AL, Moore F. Factors associated with cardiac mortality in developed countries with particular reference to the consumption of wine. Lancet 1979;1(8124): $1017-1020$

65. Di Castelnuovo A, Rotondo S, Iacoviello L, Donati MB, De Gaetano G. Meta-analysis of wine and beer consumption in relation to vascular risk. Circulation 2002;105(24):28362844

66. Di Castelnuovo A, Iacoviello L, de Gaetano G. Alcohol and coronary heart disease. N Engl J Med 2003;348(17):17191722; author reply 1719-1722

67. Corrao G, Bagnardi V, Zambon A, La Vecchia C. A metaanalysis of alcohol consumption and the risk of 15 diseases. Prev Med 2004;38(5):613-619

68. Grønbaek M, Di Castelnuovo A, Iacoviello L, et al. Wine, alcohol and cardiovascular risk: open issue. J Thromb Haemost 2004;2(11):2041-2048

69. Grønbaek M, Becker U, Johansen D, et al. Type of alcohol consumed and mortality from all causes, coronary heart disease, and cancer. Ann Intern Med 2000;133(6): 411-419

70. Mukamal KJ, Conigrave KM, Mittleman MA, et al. Roles of drinking pattern and type of alcohol consumed in coronary heart disease in men. N Engl J Med 2003; 348(2):109-118

71. Klatsky AL, Friedman GD, Armstrong MA, Kipp H. Wine, liquor, beer, and mortality. Am J Epidemiol 2003;158(6): 585-595

72. Renaud SC, Guéguen R, Siest G, Salamon R. Wine, beer, and mortality in middle-aged men from eastern France. Arch Intern Med 1999;159(16):1865-1870

73. Thun MJ, Peto R, Lopez AD, et al. Alcohol consumption and mortality among middle-aged and elderly U.S. adults. N Engl J Med 1997;337(24):1705-1714

74. Djoussé L, Lee IM, Buring JE, Gaziano JM. Alcohol consumption and risk of cardiovascular disease and death in women: potential mediating mechanisms. Circulation 2009; 120(3):237-244

75. Opie LH, Lecour S. The red wine hypothesis: from concepts to protective signalling molecules. Eur Heart J 2007; 28(14):1683-1693

76. Di Castelnuovo A, Costanzo S, Bagnardi V, Donati MB, Iacoviello L, de Gaetano G. Alcohol dosing and total mortality in men and women: an updated meta-analysis of 34 
prospective studies. Arch Intern Med 2006;166(22):24372445

77. Booyse FM, Parks DA. Moderate wine and alcohol consumption: beneficial effects on cardiovascular disease. Thromb Haemost 2001;86(2):517-528

78. Wu JM, Wang ZR, Hsieh TC, Bruder JL, Zou JG, Huang YZ. Mechanism of cardioprotection by resveratrol, a phenolic antioxidant present in red wine [review]:Int J Mol Med 2001; 8(1):3-17

79. de Gaetano G, Cerletti C; European project. FAIR CT 97 3261 Project participants. Wine and cardiovascular disease. Nutr Metab Cardiovasc Dis 2001;11(4, suppl):47-50

80. da Luz PL, Coimbra SR. Wine, alcohol and atherosclerosis: clinical evidences and mechanisms. Braz J Med Biol Res 2004;37(9):1275-1295

81. Kloner RA, Rezkalla SH. To drink or not to drink? That is the question Circulation 2007;116(11):1306-1317
82. van de Wiel A, de Lange DW. Cardiovascular risk is more related to drinking pattern than to the type of alcoholic drinks. Neth J Med 2008;66(11):467-473

83. Karatzi KN, Papamichael CM, Karatzis EN, et al. Red wine acutely induces favorable effects on wave reflections and central pressures in coronary artery disease patients. Am J Hypertens 2005;18(9 Pt 1):1161-1167

84. Papamichael C, Karatzi K, Karatzis E, et al. Combined acute effects of red wine consumption and cigarette smoking on haemodynamics of young smokers. J Hypertens 2006;24(7): 1287-1292

85. Agewall S, Wright S, Doughty RN, Whalley GA, Duxbury M, Sharpe N. Does a glass of red wine improve endothelial function? Eur Heart J 2000;21(1):74-78

86. Hashimoto M, Kim S, Eto M, et al. Effect of acute intake of red wine on flow-mediated vasodilatation of the brachial artery. Am J Cardiol 2001;88(12):1457-1460, A9 